\title{
Over-the-scope-clipping in colonic perforation caused small-bowel fixation and pneumoperito- neum requiring surgical repair
}

Perforations during endoscopy can be treated using through-the-scope clips or the over-the-scope clip (OTSC) [1-3]. The rate of successful perforation closure using the OTSC has been reported to be approximately $89 \%$ with an acceptable morbidity and mortality rate of $3 \%[3,4]$. Nevertheless, this method may also entail some risks, as shown here in a 62-year-old man who was referred for colonoscopy because of abdominal pain and melena. During diagnostic colonoscopy a 3-mm perforation ostium was noticed in the sigmoid ( Fig. 1). The colonoscope was withdrawn and an OTSC (OTSC System Set 11/6 a; Ovesco, Tübingen, Germany) was then applied via suction to the colonic wall and the ostium of the perforation. The ostium was placed directly within the cap of the OTSC and the defect appeared to be completely closed ( $\bullet$ Fig. 2 and Fig.3). However, a polypoid intraluminal yellowish structure was noticed and was interpreted as mesenteric fat ( $\bullet$ Fig.4). Abdominal pain occurred postinterventionally and a radiograph showed free intra-abdominal air. At abdominal computed tomography (CT) the small intestine appeared to be fixed to the colon, and along the right edge a substantial amount of air and fluid was noticed near the colon. Sigmoid resection was performed immediately with creation of a descendostomy (outlet from the descending colon) and blind closure of the rectum. Intraoperatively, the small intestine was found to be tightly fixed to the colon and showed signs of strong tension. Also, surprisingly, a consequent small-bowel perforation was found and this was sutured. Histopathological examination showed a fresh transmural wall defect in the sigmoid colon with hemorrhage and local peritonitis.

Although the successful use of the OTSC has been described for many indications [1 -6], this case demonstrates a major adverse effect of OTSC application. The sucking of mobile small intestine towards the ostium of the colonic perforation, brought about the previously unreported occurrence of inadvertent fixation of the small intestine to the colon with subsequent perforation of the small bowel. Possibly, a slower closure of the perforation using the "Twin Grasper" or the "OTSC Anchor," rather than the fast method using strong suction only that was applied in this case, would have avoided this major complication. Therefore, in colonic perforations separate approximation of each wound edge, using the "Twin Grasper" with good visualization, is warranted before release of the OTSC.

Endoscopy_UCTN_Code_CPL_1AJ_2AH

Competing interests: None

\section{Heinz Albrecht ${ }^{1, *}$, Andreas Naegel ${ }^{1, *}$, Alexander Hagel ${ }^{1}$, Wolf Roesler ${ }^{2}$, Thomas Foertsch $^{3}$, Markus F. Neurath ${ }^{1}$, Raja Atreya ${ }^{1}$, Martin Raithel ${ }^{1}$}

${ }^{1}$ Department of Medicine 1, University of Erlangen-Nuremberg, Germany

${ }^{2}$ Department of Medicine 5, University of Erlangen-Nuremberg, Germany 3 Department of Surgery, University of Erlangen-Nuremberg, Germany

\section{References}

1 Mönkemüller K, Peter S, Toshniwal J et al. Multipurpose use of the 'bear claw' (overthe-scope-clip system) to treat endoluminal gastrointestinal disorders. Dig Endosc 2013. doi: 10.1111/den.12145. Epub ahead of print 16 Jul 2013

2 Weiland T, Fehlker M, Gottwald T et al. Performance of the OTSC system in the endoscopic closure of iatrogenic gastrointestinal perforations: a systematic review. Surg Endosc 2013; 27: 2258-2274

3 Voermans RP, Le Moine $O$, von Renteln D. CLIPPER Study Group et al. Efficacy of endoscopic closure of acute perforations of the gastrointestinal tract. Clin Gastroenterol Hepatol 2012; 10: 603-608

4 Hagel AF, Naegel A, Lindner AS et al. Overthe-scope clip application yields a high rate of closure in gastrointestinal perforations and may reduce emergency surgery. J Gastrointest Surg 2012; 16: 2132-2138

* These authors contributed equally to this work.

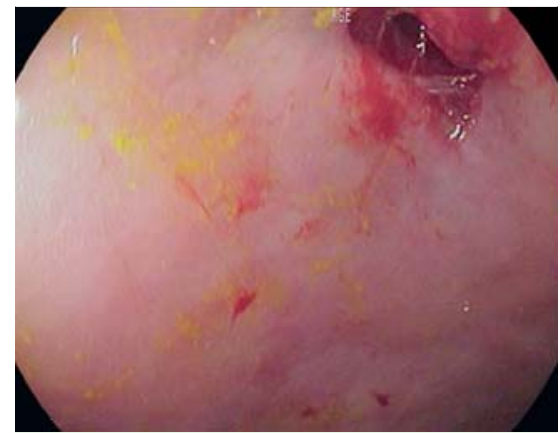

Fig. 1 A 3-mm perforation was seen in the sigmoid colon.

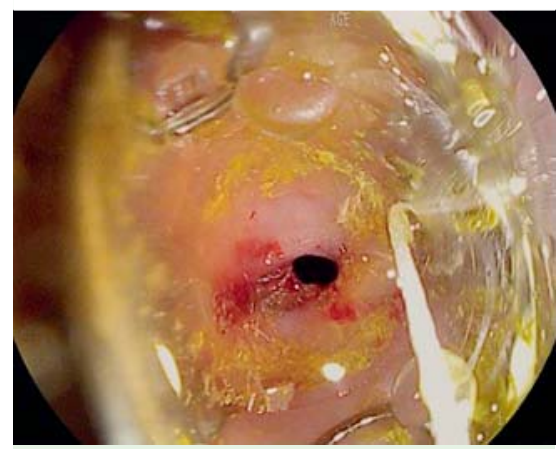

Fig. 2 The perforation was positioned within the cap of the over-the-scope clip (OTSC).

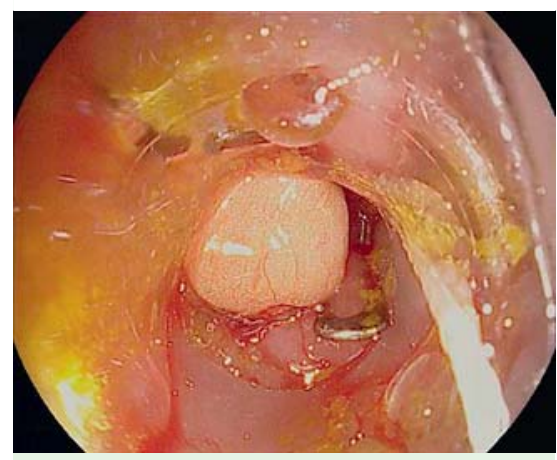

Fig. 3 Complete closure of the colonic perforation with the over-the-scope clip (OTSC).

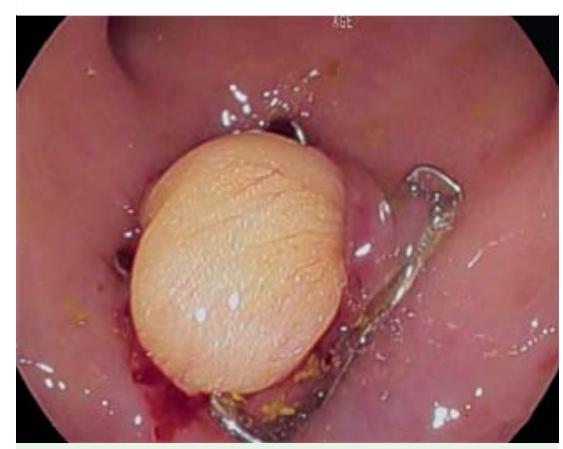

Fig.4 A polypoid intraluminal yellowish structure was seen after closure of the colonic perforation with the over-the-scope clip (OTSC). 
5 Kothari TH, Haber G, Sonpal N et al. The overthe-scope clip system - a novel technique for gastrocutaneous fistula closure: the first North American experience. Can J Gastroenterol 2012; 26: 193 - 195

6 Tontini GE, Naegel A, Albrecht $H$ et al. Successful over-the-scope clip (OTSC) treatment for severe bleeding due to anastomotic dehiscence. Endoscopy 2013; 45 (Suppl. 02): E343-344
Bibliography

Dol http://dx.doi.org/

10.1055/s-0034-1377218

Endoscopy 2014; 46: E314-E315

(c) Georg Thieme Verlag KG

Stuttgart · New York

ISSN 0013-726X
Corresponding author

Heinz Albrecht, MD

Department of Medicine 1

University of Erlangen-Nuremberg

Ulmenweg 18, 91054 Erlangen

Germany

Fax: +49-91-318535252

heinz.albrecht@uk-erlangen.de 